\title{
Freqüiência de anticorpo anti-Toxocara canis em comunidade do Rio Uatumã, no Estado do Amazonas
}

\author{
Frequency of the antibody anti-Toxocara canis in a community along \\ the Uatumã River, State of Amazonas
}

\author{
Márcia Melo Damian ${ }^{1,2}$, Marilaine Martins ${ }^{1}$, José Felipe Sardinha1, \\ Luciana Orêncio de Souza ${ }^{1}$, Andreza Chaves ${ }^{1}$ e Antonio de Matos Tavares ${ }^{1}$
}

\begin{abstract}
RESUMO
Um estudo seccional foi realizado nas Vilas Waimiri e Atroari em Balbina, entre julho e outubro de 2006, com o objetivo de estimar a freqüência de anticorpo antiToxocara canis da classe IgG e avaliar as variáveis epidemiológicas e socioculturais. Foram estudadas 34 famílias e incluídos 100 indivíduos, o que correspondeu a 5\% (100/2.000) da população das vilas. A idade variou de zero a 76 anos (M=22,9 Dp=18). Quanto ao gênero, 53\% eram femininos e 47\% masculino; $52 \%$ das amostras foram positivas para Toxocara canis, 44,5\% negativas e 3,2\% inconclusivas. Observou-se menor número de indivíduos com sorologia negativa na Vila Atroari 29,5\% (13/44) em comparação com a Waimiri 46,4\% (26/56). Com relação ao contato com cães, dos 55 indivíduos com contato domiciliar 60\% (33/55) foram positivos para anticorpo

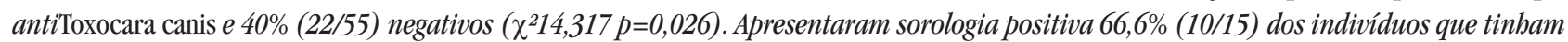
contato domiciliar com filhotes de cão $\left(\chi^{222,149} p=0,008\right)$. A existência de contato domiciliar com cães e filhotes mostrou associação com a presença de anticorpo anti-Toxocara canis na população estudada.
\end{abstract}

Palavras-chaves: Toxocara canis. Toxocaríase. Sorologia.

\begin{abstract}
A cross-sectional study was carried out in the Waimiri and Atroari settlements in Balbina, between July and October 2006, with the aims of estimating the frequency of the antibody anti-Toxocara canis of the IgG class and studying the epidemiological and sociocultural variables. Thirty-four families were studied and 100 individuals were included, corresponding to 5\% (100/2000) of the population of the settlements. The age range was 0-76 years $($ mean $=22.9$; standard deviation $=18)$. The gender distribution was 53\% female and $47 \%$ male. The samples were $52 \%$ positive for Toxocara canis, $44.5 \%$ negative and 3.2\% inconclusive. The number of individuals who tested serologically negative in Atroari (29.5\%; 13/44) was lower than in Waimiri (46.4\%; 26/56). In relation to contact with dogs, among the 55 individuals with contact in their homes, 60\% (33/55) were positive for Ac anti-Toxocara canis and 40\% (22/55) were negative $\left(\chi^{2}=14.317 ; p=0.026\right)$. Among the individuals who had contact in their homes with puppies, $66.6 \%(10 / 15)$ were serologically positive $\left(\chi^{2}=22.149 ; p=0.008\right)$. The existence of home contact with dogs and puppies showed an association with the presence of Ac anti-Toxocara canis in the study population.
\end{abstract}

Key-words: Toxocara canis. Toxocariasis. Serology.

A toxocaríase é uma antropozoonose, que ocorre em diversas regiões do mundo, causada por geohelminto que parasita cães e gatos, eventualmente afetando humanos ${ }^{1}$.

Descrita por Beaver em 1952, a larva migrans visceral (LMV) humana, também denominada toxocaríase, era uma doença considerada rara. No entanto, atualmente, encontra-se em expansão e, na grande maioria dos casos, comporta-se como uma doença benigna de curso limitado, embora exista casos graves e fatais ${ }^{2}$.

Entre os nematelmintos pertencentes à família Ascaridea, 0 gênero Toxocara apresenta-se como o mais prevalente, sendo as espécies Toxocara canis e Toxocara catti respectivamente ascarídeos de cães e gatos, que são os hospedeiros definitivos. A infecção entre os cães é observada com maior frequiência em

1. Fundação de Medicina Tropical do Amazonas, Manaus, AM. 2. Curso de Pós graduação em Medicina Tropical e Doenças Infecciosas da Universidade do Estado do Amazonas, Manaus, AM.

Apoio financeiro: Fundação de Amparo à Pesquisa do Amazonas (FAPEAM) e Fundação de Medicina Tropical do Amazonas (FMTAM).

Endereço para correspondência: Dra. Márcia Melo Damian. Fundação de Medicina Tropical do Amazonas. Av. Pedro Teixeira 25, D. Pedro, 69040-000 Manaus, AM.

Tel: 5592 2127-3489; Fax: 5592 3238-2824.

e-mail: jorgemarcia@uol.com.br

Recebido para publicação em: 19/04/2007

Aceito em: 11/10/2007 
cadelas prenhes e lactantes, assim como, em filhotes. Nestes, a contaminação ocorre por via transplacentária e transmamária, sendo as maiores prevalências de carga parasitária observadas em filhotes na idade de três a seis meses. Os filhotes de cães infectados completam o ciclo em três a quatro semanas após o nascimento, quando são capazes de eliminar ovos de Toxocara canis nas fezes para 0 meio ambiente ${ }^{35}$.

Os hospedeiros paratênicos ou intermediários, particularmente o homem, se infectam e entram no ciclo do parasita de forma acidental. Os ovos contendo L2, ao chegarem ao intestino delgado do homem, liberam estas formas larvárias, que são capazes de ativamente atravessarem a mucosa intestinal e, por via linfática, atingirem a circulação porta e, por conseguinte, o fígado. Essas larvas saem do fígado ganham à circulação sangüínea chegando aos pulmões. Atravessam os capilares pulmonares e caem na circulação pulmonar, coração esquerdo, disseminando-se para todo o organismo pela circulação sistêmica. Quando o tamanho das larvas de Toxocara canis excede o diâmetro dos capilares sangüíneos, ocorre uma migração ativa e errática através da parede celular e dos tecidos do hospedeiro. A fase de migração larvária ocasiona uma reação inflamatória aguda, com presença de eosinófilos, neutrófilos e, algumas vezes, monócitos. Também, nesta fase há liberação de produtos metabolicamente ativos e antigênicos denominados antígenos de secreção-excreção (antígenos TES), que são proteínas glicosiladas e proteases. Foi demonstrado que esses Ag TES localizam-se na epicutícula das larvas e são receptores importantes para anticorpos ${ }^{67}$.

0 diagnóstico da infecção humana por Toxocara canis é feito por métodos indiretos, com detecção de níveis elevados de anticorpo IgG antiToxocara canis no sangue ou fluídos biológicos dos pacientes. Estes anticorpos podem ser detectados por diversas técnicas; dentre as mais utilizadas estão os métodos ELISA (enzime liked inmuno assay) e o EIA (enzime inmuno assay). Atualmente, no teste ELISA tem sido usado antígeno TES da larva adsorvido do soro com antígeno de Ascaris suum, que mostra sensibilidade de $80 \%$ e especificidade de $90 \%$, sendo mais indicado do que o teste que utiliza o antígeno total da larva, desde que possa haver reação cruzada com leishmaniose, esquistossomose, doença de Chagas, malária, ascaridíase, dentre outras patologias tropicais ${ }^{2}$.

Os objetivos deste estudo foram avaliar a frequiência de anticorpos antiToxocara canis em indivíduos residentes nas Vilas Waimiri e Atroari em Balbina, município de Presidente FigueiredoAmazonas, e investigar quais as variáveis epidemiológicas e socioculturais relevantes para ocorrência desta zoonose.

\section{MATERIAL E MÉTODOS}

Este trabalho foi submetido ao Comitê de Ética em Pesquisa da Fundação de Medicina Tropical do Amazonas e aprovado de acordo com o Protocolo n ${ }^{\circ} 1166 / 06$. Aárea do estudo foram as vilas Waimiri e Atroari em Balbina, pertencente a município de Presidente Figueiredo, localizada na AM-240, Reserva Biológica do Rio Uatumã/REBIO.

0 modelo de estudo foi seccional. Foram incluídos para amostra 100 indivíduos, o que correspondeu a 5\% (100/2000) da população, tendo em consideração que não há estudos similares na região. Os critérios de inclusão foram indivíduos de qualquer idade, sexo ou raça, residente nas vilas de Balbina há mais de seis meses e que assinaram o termo de consentimento livre e esclarecido. Os critérios de exclusão foram indivíduos não residentes nas Vilas de Balbina ou residentes há menos de seis meses.

Foram sorteadas aleatoriamente as casas nas Vilas Atroari e Waimiri. Essa distribuição foi necessária tendo em vista que moradores da Vila Atroari residem em casas de madeira e têm condições socioeconômicas menos favorecidas, enquanto os residentes na Vila Waimiri têm melhores habitações, constituídas por casas de alvenaria, e condições socioeconômicas mais privilegiadas. Com relação à rede de esgoto, fossa séptica, coleta e destino do lixo e água para consumo, existem semelhança entre as casas de ambas as vilas.

Após sorteio, foi aplicado um questionário individual contemplando dados de identificação, epidemiológicos e socioculturais e coletado cinco mililitros de sangue, assim como entregue um frasco com formalina para coleta de fezes. As amostras de soro humano coletadas em campo foram armazenadas congeladas após centrifugação e, posteriormente, transportadas para a Fundação de Medicina Tropical do Amazonas, em Manaus, para execução dos testes.

Para a realização da sorologia, utilizou-se o KIT comercial RIDESCREEN ® Toxocara IgG, $\mathrm{N}^{\circ}$ do artigo K7421, R-Biopharm AG, Landwehrstr. 54, D-64293 Darmstadt, Alemanha, cuja finalidade é a detecção de anticorpo anti-Toxocara canis da classe IgG através da técnica de ensaio imuno enzimático (EIA).

0 resultado foi interpretado com índice das amostras (D0) negativo $<0,9$; duvidoso $0,9-1,1$; e positivo $>1,1$. Os soros controle positivo e negativo contidos no KIT foram testados para 0 vírus da imunodeficiência humana (HIV), vírus da hepatite $\mathrm{C}$ (HCV) e antígeno de superfície do vírus da hepatite B (HbsAg), que foram negativos. Para o controle de qualidade, foi realizado controle positivo e negativo em duplicata.

As amostras de fezes foram examinadas no laboratório da Gerência de Parasitologia da Fundação de Medicina Tropical do Amazonas, pelos métodos de Lutz e Willis.

A análise foi realizada com o pacote estatístico SPSS versão 10.0 e EPINFO versão 2000, com nível de significância de 0,05 (valor de p) e intervalo de confiança de $95 \%$ (IC). Os testes exato de Fischer e qui-quadrado $\left(\chi^{2}\right)$ foram utilizados para as variáveis qualitativas. Para mensurar a associação entre as variáveis socioeconômicas e culturais e a soropositividade para Toxocara canis, utilizou-se o coeficiente de correlação de Pearson.

\section{RESULTADOS}

Foram avaliadas 34 famílias e entrevistados 100 indivíduos residentes nas Vilas de Balbina, distribuídos em 56\% na Vila Waimiri e 44\% na Atroari. Quanto ao gênero, 53\% era feminino e $47 \%$ masculino. A idade variou de um a 76 anos, com média de 22,9 (Dp 18,3). Duas crianças tinham menos de um ano. A faixa 
etária mais prevalente foi 6-10 anos e 45\% dos indivíduos incluídos na pesquisa tinham menos de 15 anos de idade (Tabela 1).

o tempo de moradia na região dos indivíduos incluídos na pesquisa variou de um a 38 anos, com média de 9,2 anos, sendo que $11 \%$ tinham menos de um ano de residência e $87 \%$ residiam a mais de um ano.

Tabela 1 - Distribuição dos indivíduos segundo a faixa etária, nas vilas Waimiri e Atroari em Balbina, de julbo a outubro de 2006.

\begin{tabular}{|c|c|c|c|c|c|c|}
\hline \multirow{2}{*}{$\begin{array}{l}\text { Faixa etária } \\
\text { (anos) }\end{array}$} & \multicolumn{4}{|c|}{ Sorologia Toxocara canis } & \multirow[b]{2}{*}{ Total } & \multirow{2}{*}{$\begin{array}{c}P \\
\text { (valor) }\end{array}$} \\
\hline & indeterminada & negativa & positiva & não realizada & & \\
\hline $0-5$ & & 8 & 4 & 5 & 17 & 0,09 \\
\hline $6-10$ & 1 & 6 & 6 & 4 & 17 & 0,67 \\
\hline $11-15$ & & 4 & 8 & & 12 & 0,41 \\
\hline $16-20$ & & 2 & 6 & & 8 & 0,22 \\
\hline $21-25$ & & 2 & 7 & & 9 & 0,14 \\
\hline $26-30$ & & 4 & 3 & & 7 & 0,37 \\
\hline $31-35$ & 1 & 4 & 1 & & 6 & 0,11 \\
\hline $36-40$ & & 2 & 3 & & 5 & 0,598 \\
\hline $41-45$ & & 2 & 1 & & 3 & 0,414 \\
\hline $46-50$ & & 1 & 2 & & 3 & 0,601 \\
\hline $51-55$ & 1 & 1 & 2 & & 4 & 0,601 \\
\hline $56-60$ & & 1 & 4 & & 5 & 0,259 \\
\hline$>60$ & & & 2 & & 2 & 0,307 \\
\hline Total & 3 & 39 & 49 & 9 & 100 & \\
\hline
\end{tabular}

A positividade da sorologia para Toxocara canis foi semelhante em ambas as vilas, com predominância na Vila Atroari, no entanto, sem diferença estatisticamente significativa (Tabela 2).

Tabela 2 - Freqüência de anticorpos antiToxocara canis nas vilas Waimiri e Atroari em Balbina, de julbo a outubro de 2006.

\begin{tabular}{|c|c|c|c|c|c|c|c|c|c|c|}
\hline \multirow{3}{*}{ Vilas } & \multicolumn{10}{|c|}{ Sorologia para Toxocara canis } \\
\hline & \multicolumn{2}{|c|}{ positiva } & \multicolumn{2}{|c|}{ negativa i } & \multicolumn{2}{|c|}{ indeterminada } & \multicolumn{2}{|c|}{ não realizada } & \multicolumn{2}{|c|}{ Total } \\
\hline & $\overline{\mathrm{n}^{0}}$ & $\%$ & $\overline{\mathrm{n}^{0}}$ & $\overline{\%}$ & $\mathrm{n}^{0}$ & $\%$ & $\mathrm{n}^{0}$ & $\%$ & $\overline{n^{0}}$ & $\%$ \\
\hline Waimiri & 24 & 42,8 & 26 & 46,4 & 2 & 3,5 & 4 & 7,1 & 56 & 100,0 \\
\hline Atroari & 25 & 56,8 & 13 & 29,5 & 1 & 2,2 & 5 & 11,3 & 44 & 100,0 \\
\hline
\end{tabular}

A média de idade dos indivíduos com sorologia positiva foi semelhante à daqueles com sorologia negativa, sendo observada maiores porcentagens de positividade na faixa etária de 11 a 15 anos com 16,3\% e de 21 a 25 com 14,3 \% (Figura 1).

Na Tabela 3, estão distribuídas as características demográficas e epidemiológicas de ambas as vilas.

Do total de 100 indivíduos, apenas 40 realizaram exame parasitológico de fezes (EPF). Destes, 77,5\% (31/40) apresentaram pelo menos um parasita em uma das técnicas realizadas, sendo 22,5\% (9/40) das amostras examinadas negativas. Não foi encontrada diferença estatisticamente significativa entre positividade da sorologia para Toxocara canis e EPF positivo $\left(\chi^{2} 7,800, \mathrm{p}=0,277\right)$. Os parasitas intestinais encontrados com maior frequiência foram: Entamoeba histolyticaldispar (44), Blastocistis hominis (21), Giardia lamblia (8) e Ascaris lumbricoides (7).

A Tabela 4 demonstra as variáveis epidemiológicas estudadas, na qual se pode observar diferença estatísticamente significativa apenas com relação ao contato domiciliar com cães e filhotes.

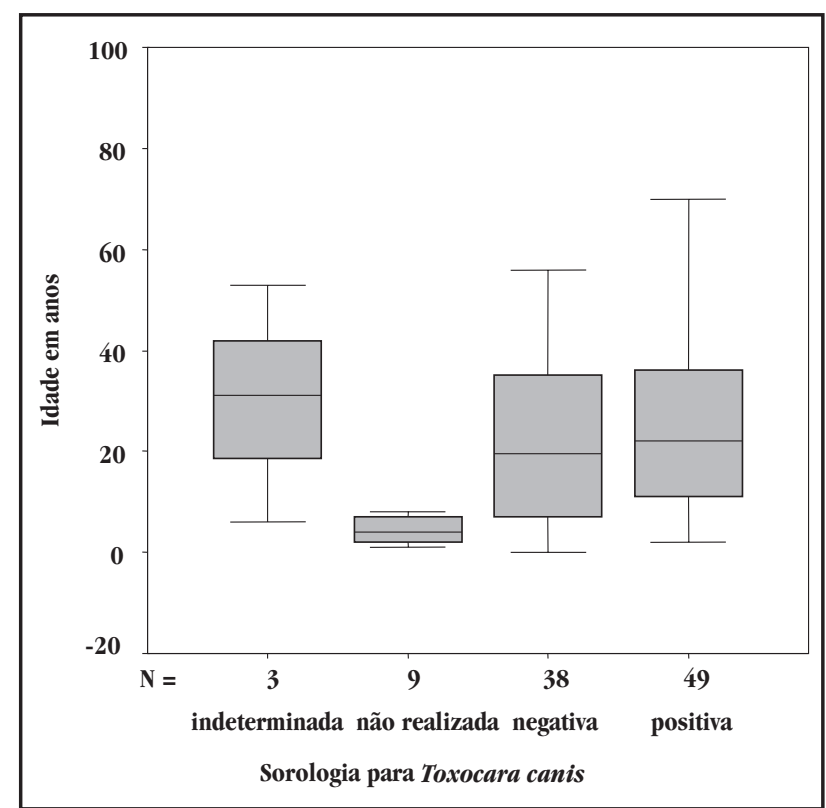

Figura 1 - Média de idade dos indivíduos com relação à pesquisa de anticorpo anti-Toxocara canis nas vilas Waimiri e Atroari em Balbina, de julbo a outubro de 2006.

Tabela 3 - Aspectos demográfico e socioculturais das vilas Waimiri e Atroari em Balbina, de julbo a outubro de 2006.

\begin{tabular}{|c|c|c|}
\hline Variáveis epidemiológicas & Vila Waimiri & Vila Atroari \\
\hline Sexo $\sigma^{\prime} / q$ & $30 / 26$ & $17 / 27$ \\
\hline Média de idade & 23,5 & 22,2 \\
\hline Crianças ( $\leq 15$ anos) & 26 & 20 \\
\hline Anda descalço (sim X não) & $30 \times 12$ & $33 \times 10$ \\
\hline Tempo de moradia $<1$ ano & 6 & 5 \\
\hline Contato com cães & 35 & 30 \\
\hline Contato com cães no domicílio & 25 & 33 \\
\hline Contato com filhotes de cães no domicílio & 1 & 14 \\
\hline Média do número de pessoas que coabitam & 6,09 & 8,57 \\
\hline
\end{tabular}

Tabela 4 - Avaliação das variáveis epidemiológicas com relação à presença de anticorpos anti Toxocara canis nas Vilas Waimiri e Atroari em Balbina, de julbo a outubro de 2006.

\begin{tabular}{lcc}
\hline Variáveis epidemiológicas & $\chi^{2}$ & Valor de $\mathrm{p}$ \\
\hline Idade < 15 anos & 0,79 & 0,37 \\
Andar descalço & 0,11 & 0,73 \\
Antiparasitário <3 meses & 0,26 & 0,60 \\
Mãe com trabalho extradomiciliar & 1,32 & 0,25 \\
Grau de escolaridade da mãe & 3,12 & 0,27 \\
Contato com águas naturais & 2,80 & 0,09 \\
Contato com cães no domicílio & 14,31 & $0,02^{*}$ \\
Contato com gatos & 0,43 & 0,51 \\
Contato com filhotes de cão no domicílio & 22,14 & $0,008^{*}$ \\
Contato com terra & 0,02 & 0,87 \\
*índice de confiança 95\%, valor de p < 0,05, diferença estatística significativa.
\end{tabular}

\section{DISCUSSÃo}

A prevalência de indivíduos saudáveis de todas as idades positivos para anticorpos antiToxocara canis através do método ELISA com antígeno solúvel de larvas, em cinco municípios de São Paulo em 1990, mostrou porcentagens de 2,2\% a 5,7\%. Enquanto outro estudo envolvendo crianças, realizado por Moreira-Silva e 
cols, em 1998 em Vitória/ES, demonstrou maiores positividades chegando a 39\%, que pode ser comparado ao das Vilas Waimiri e Atroari (52\%). Isso provavelmente se deve à grande população de cães com alta prevalência de infecção por Toxocara canis, à íntima relação com o homem, particularmente das crianças com estes animais de estimação, aos hábitos de defecação destes animais em ruas e praças públicas que conseqüentemente levam à contaminação do meio ambiente, particularmente do solo. Na literatura, não há relatos sobre a soroprevalência da toxocaríase no Amazonas e a contaminação do solo por ovos de Toxocara canis mostrou-se menor em Manaus, quando comparada com as prevalências encontradas nas regiões Nordeste, Sudeste e Sul do Brasil $^{789}$.

Apesar de os indivíduos residentes nas vilas terem tipo de habitação e nível socioeconômico diferenciados, não foi observada diferença estatística significativa $\left(\chi^{22,740} \mathrm{p}=0,098\right)$ com relação à positividade da sorologia para Toxocara canis. No entanto, observou-se maior número de indivíduos com sorologia negativa na vila Waimiri. É provável que esse achado possa ser justificado pelo menor contato com ambiente contaminado, em especial com o solo que representa a fonte de contaminação relevante para toxocaríase, pois o hábito de andar descalço e o contato com cães e seus filhotes foram relatados com menor frequiência pelos indivíduos que residem nesta vila, assim como o número de pessoas que coabitam no domicílio.

De acordo com a literatura, a infecção no homem é mais freqüiente entre as crianças do sexo masculino, na faixa etária de 2-5 anos de idade, com média de 4,6 a 3,6 anos, ocorrendo outro pico de incidência entre 35-40 anos .

Neste trabalho, a faixa etária onde houve maior freqüência de anticorpos antiToxocara canis foi 11 a 15 anos, com segundo pico de 21 a 25 anos. Porém, há necessidade de maior número de indivíduos para se ter uma conclusão mais consistente. Não se observou diferença com relação ao gênero.

Apesar de a sorologia positiva para Toxocara canis ter sido mais freqüente nos indivíduos que tinham algum parasito intestinal, não se pode inferir a possibilidade de reação cruzada, pois $60 \%$ dos indivíduos não coletaram fezes e o Ascaris, que é responsável pelo maior número de reação cruzada, foi encontrado apenas em sete amostras. Outras reações cruzadas podem ocorrer com leishmaniose, esquistossomose, doença de Chagas, malária, dentre outras patologias tropicais, no entanto nenhuma destas foi encontrada 3 .

Mostrou-se importante a presença domiciliar do cão e seus filhotes, não sendo evidenciada relação com trabalho extradomiciliar da mãe assim como o grau de escolaridade, o que também já foi demonstrado por outros autores ${ }^{4}$.

Dessa forma, o conhecimento da ocorrência da toxocaríase com ênfase aos aspectos socioculturais e comportamental que caracterizam o hábito de vida tanto individual como coletivo, sugeridos pela literatura como fatores de risco para aquisição da doença, são relevantes para compreensão deste grave problema de saúde pública pouco investigado na região amazônica.

\section{AGRADECIMENTOS}

Agradecemos ao Administrador e Representante dos moradores das Vilas de Balbina, aos funcionários e administradores do Hospital de Balbina, aos Laboratórios de Parasitologia e NB-3 da FMT-AM, pelo apoio técnico, com ajuda na coleta e execução dos exames, em particular ao bioquímico João Bosco Lima Gimaque e ao técnico Ademir Roberto Lopes Soares.

\section{REFERÊNCIAS}

1. Andrade LD. Aspectos Clínico-Epidemiológicos da Toxocaríase Humana. Revista de Patologia Tropical 29:147-159, 2000.

2. Chieffi PP, Ueda M, Camargo E, Souza A, Guedes M, Gerbi L, Spir M, Moreira A. Visceral Larva Migrans: A Soroepedemiological Survey in five Municipalities of São Paulo State, Brazil. Revista do Instituto de Medicina Tropical de São Paulo 32:204-210, 1990.

3. De Savigny D, Tizard I. Toxocaral Larva Migrans: The use of Larval Secretory Antigens in Hemagglutination and Soluble Antigens Fluorescent Antibody tests. Translation Real Society Tropical Medicine Hygiene 71:501-507, 1977.

4. Figueiredo SD, Taddei JA, Menezes JJ, Novo NF, Silva E0, Cristóvão HL, Cury MC. Estudo clínico-epidemiológico da toxocaríase em população infantil. Jornal de Pediatria 81:126-132, 2005.

5. Glickman LT. The Epidemiology of Human Toxocariasis. Toxocara and Toxocariasis - Clinical, Epidemiological and Molecular perspectives. British Parasitological Society and Institute of Biology, p.3-10, 1993.

6. Lambertucci JR. Hipergamaglobulinemia E, Doenças Parasitárias e Infecção Estafilocóccica. Revista da Sociedade Brasileira de Medicina Tropical 29:107$210,1996$.

7. Magnaval JF, Michault A, Calon N, Charlet JP. Epidemiology of Human Toxocariasis in La Réunion. Translation Real Society Tropical Medicine Hygiene 88:531-533, 1994.

8. Martins M, Soares AR, Moura MA, Chaves AC, Silva RS, Barros JA. Levantamento de Toxocara canis no município de Manaus-AM. In: Prata A (ed) Anais do XXXIX Congresso da Sociedade Brasileira de Medicina Tropical; Belém, PA, p.194-195, 2003 .

9. Moreira S, Pereira F. Abscesso Piogênico do Fígado e Toxocaríase: Estudo de $\mathbf{1 3}$ Casos e 110 Controles do mesmo Hospital. Revista da Sociedade Brasileira de Medicina Tropical 32 (supl I):62-63, 1999. 